05

\title{
Влияние температуры деформации В камере Бриджмена на особенности формирования дефектной структуры технически чистого титана
}

\author{
(C) Н.А. Шурыгина ${ }^{1}$, А.М. Глезер ${ }^{1,2, q}$, Д.Л. Дьяконов ${ }^{1}$, \\ А.А. Томчук ${ }^{1,3}$, А.Г. Кадомцев ${ }^{4}$, М.В. Нарыкова ${ }^{4}$ \\ ${ }^{1}$ Центральный научно-исследовательский институт черной металлургии \\ им. И.П. Бардина, Москва, Россия \\ ${ }^{2}$ Национальный исследовательский технологический университет \\ „МИСиС“, Москва, Россия \\ ${ }_{3}^{3}$ Московский государственный технический университет \\ им. Н.Э. Баумана, Москва, Россия \\ ${ }^{4}$ Физико-технический институт им. А.Ф. Иофрфе РАН, \\ Санкт-Петербург, Россия \\ ฯ E-mail: a.glezer@mail.ru
}

Поступило в Редакцию 28 мая 2018 г.

Методом просвечивающей электронной микроскопии установлено образование в структуре $\alpha$-фазы после кручения под высоким гидростатическим давлением при комнатной и криогенной температурах областей структуры, соответствующих деформационным фрагментам и динамически рекристаллизованным зернам. Показана применимость к описанию дефектных структур модели „двухфазной смеси“.

DOI: 10.21883/PJTF.2018.20.46808.17409

Повышение прочности чистых металлов, в том числе титана, до уровня прочности сильно легированных сплавов возможно путем различных экстремальных воздействий на объемный материал. К таким воздействиям можно отнести большую пластическую деформацию и деформирование при низких (криогенных) температурах.

Один из распространенных способов создания больших степеней деформации - кручение под высоким давлением (КВД) в камере Бриджмена [1]. Особенностью больших пластических деформаций ме- 
таллов и сплавов является образование фрагментированных структур с субмикронным размером сильно разориентированных фрагментов [2], а также одновременное протекание динамических рекристаллизационных процессов при комнатных температурах [3].

В настоящее время нет надежных литературных данных, касающихся сравнительного статистического анализа эволюции дефектной структуры поликристаллического титана в процессе КВД при различных (комнатных и криогенных) температурах. Интерес к исследованию структурных превращений в титане и его сплавах при низких температурах обусловлен востребованностью высокопрочных титановых сплавов в авиа- и космической отраслях.

Целью настоящей работы является детальное изучение эволюции дефектной структуры поликристаллического $\alpha$-Ті под воздействием КВД в камере Бриджмена при различных величинах и температурах деформации с использованием статистического анализа темнопольных электронно-микроскопических изображений. В качестве материала для исследования был выбран технически чистый титан ВТ1-0 ( $\alpha$-фаза), в котором на процессы структурообразования при пластической деформации в минимальной степени влияют атомы примесей или избыточные фазы. Образцы в виде пластин толщиной $50 \mu \mathrm{m}$ были подвергнуты деформации КВД $(P=6 \mathrm{GPa})$ в камере Бриджмена при комнатной температуре $(293 \mathrm{~K})$ и температуре кипения жидкого азота $(77 \mathrm{~K})$ со скоростью вращения подвижного бойка $1 \mathrm{rpm}$ при числе оборотов подвижной наковальни $N=1 / 4,1 / 2,1,2,3$ и 4, что соответствовало интервалу значений истинных деформаций $e=5.5-8.3$ [1]. Структурные исследования проводились с помощью просвечивающего электронного микроскопа JEM 200CX при ускоряющем напряжении $160 \mathrm{kV}$. Все исследования локальной структуры выполнялись в областях, примерно соответствующих половине радиуса дискообразных образцов.

Микроструктура титана после КВД при 293 и $77 \mathrm{~K}$ представляет собой смесь $\alpha$ - и $\omega$-фаз. Участки $\omega$-фазы имеют неправильную форму с характерным полосчатым контрастом внутри частиц [4]. При детальном электронно-микроскопическом анализе микроструктуры $\alpha$-Ti на всех стадиях КВД при различных температурах деформации нами обнаружено, что на темнопольных изображениях четко выявляются отдельные зерна, имеющие форму почти правильных шестиугольников (зерна 1 и 2 на рис. $1, a$ ). Внутри этих зерен плотность дислокаций 

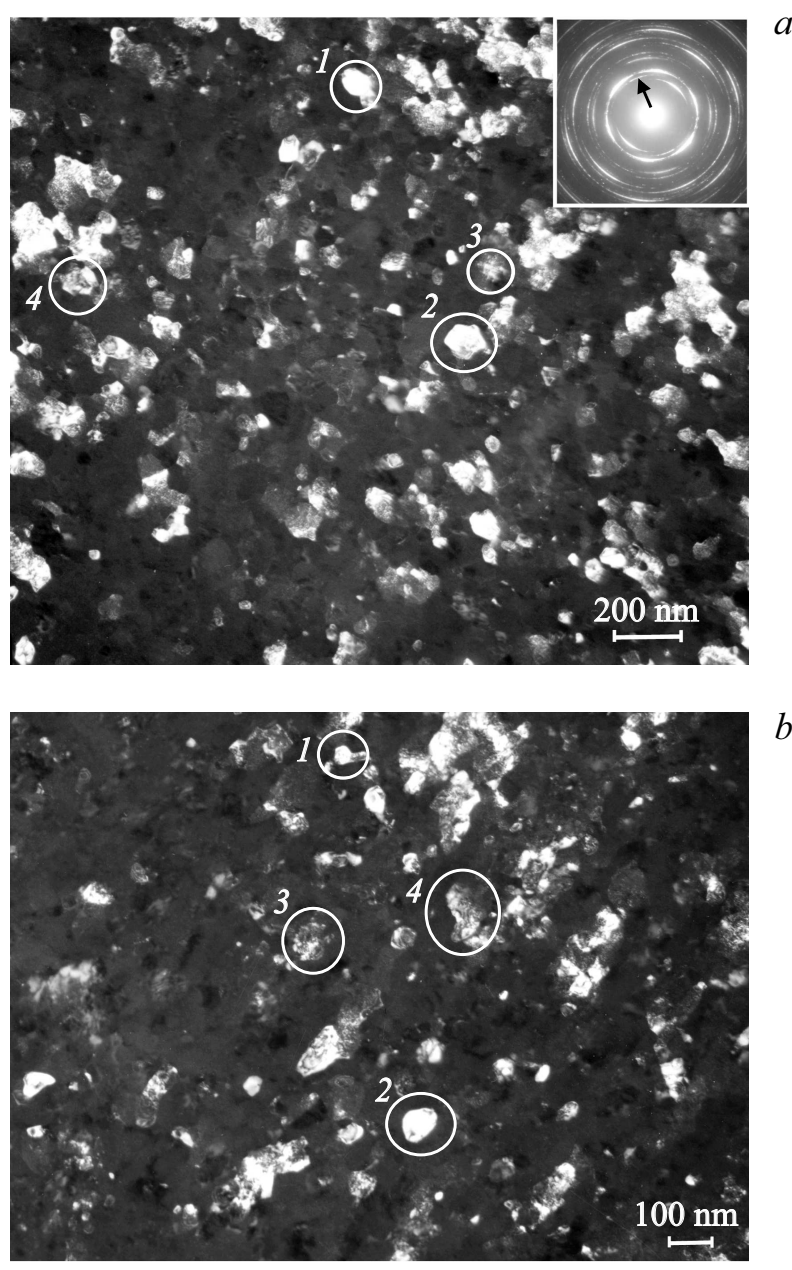

Рис. 1. Темнопольное электронно-микроскопическое изображение структуры $\alpha$-Ті и соответствующая микроэлектронограмма после КВД $(N=4)$ при различных температурах деформации. $T, \mathrm{~K}: a-293, b-77$. Стрелкой указан действующий рефлекс (100) $\alpha .1,2$ - рекристаллизованные зерна, 3, 4 дислокационные фрагменты. 
низкая, что, очевидно, свидетельствует о том, что они сформировались в результате динамической рекристаллизации в процессе КВД. Такого рода рекристаллизация, обозначаемая как непрерывная [5], может быть рассмотрена как релаксационный процесс в условиях значительных градиентов упругих напряжений внутри деформационных фрагментов [6]. Такие рекристаллизованные зерна наблюдаются нами в $\alpha$-Ті даже после КВД в условиях криогенных температур (зерна 1 и 2 на рис. $1, b)$.

В то же время некоторые участки структуры на темнопольных снимках (зерна 3 и 4 на рис. $1, a, b)$ следует отнести к так называемым деформационным фрагментам. Они имеют неправильную форму, сильно искаженные приграничные области обнаруживают высокую плотность дислокационной структуры и значительные внутризеренные разориентировки. Это, безусловно, свидетельствует об их деформационном происхождении в результате деформационной фрагментации [2].

В работе [7] для объяснения специфики структуры, формирующейся при КВД, была предложена модель „двухфазной смеси“. Суть этой модели заключается в том, что структура материала, формирующаяся при КВД, состоит как бы из двух „фаз“: деформационных фрагментов, образовавшихся в результате дисклинационно-дислокационных перестроек в процессе пластического течения, и динамически рекристаллизованных зерен, возникших как реализация дополнительного эффективного канала релаксации упругой деформации по механизму непрерывной низкотемпературной рекристаллизации.

В связи с этим довольно интересным и важным представляется вопрос о том, какими структурными параметрами могут быть охарактеризованы эти „фазы“ в зависимости от величины и температуры непрерывной деформации КВД. Для установления структурных параметров деформационных фрагментов (ДФ) и рекристаллизованных зерен (Р3) мы воспользовались методикой, предложенной Глезером и Томчуком [7].

Каждый из двух типов структурных составляющих (ДФ и РЗ), имея различную природу образования, должен характеризоваться, очевидно, своей характерной функцией распределения по размерам этих структурных элементов. На основе данных просвечивающей электронной микроскопии были получены гистограммы распределения зерен и фрагментов по размерам как при комнатной температуре, так и при криогенной

Письма в ЖТФ, 2018, том 44, вып. 20 
температуре КВД. Полученные гистограммы на самом деле являются комбинированными и состоят из двух гистограмм распределения: одно распределение для ДФ, другое для РЗ.

На основании расчета относительных площадей под гауссовыми распределениями были определены относительные объемные доли деформационных фрагментов $C_{F}$ и рекристаллизованных зерен $C_{R G}$ для каждого режима деформирования (рис. 2), а также средний размер областей, соответствующий фрагментам $D_{F}$ и рекристаллизованным зернам $D_{R G}$ (рис. 3 ). Как следует из рис. $3, b$, в процессе КВД при $77 \mathrm{~K}$ наблюдается участок $(2<N<4)$ заметного снижения значения $D_{F}$, что связано, по-видимому, с затруднением в образовании ДФ в процессе мегапластической деформации. Можно предполагать, что при низкотемпературной деформации в определенной степени затрудняется протекание релаксационных процессов.

Проведенное в настоящей работе электронно-микроскопическое исследование фрагментированной структуры $\alpha$-фазы со всей очевидностью показало корректность описания структурных превращений на различных стадиях КВД с помощью ранее предложенной модели „двухфазной смеси“, которая реализуется в железе и его сплавах [7]. $\mathrm{C}$ ее помощью нам удалось проследить за эволюцией деформационных фрагментов и динамически рекристаллизованных зерен по мере роста величины деформации $N$ при различных температурах КВД. Самым поразительным оказалось то, что непрерывная динамическая рекристаллизация в процессе КВД протекает не только при комнатных, но и при криогенных температурах деформирования $(77 \mathrm{~K})$. Как видно из рис. $2, b$, при низких температурах наблюдается стадия, когда практически весь объем деформированной $\alpha$-фазы состоит из ДФ $\left(C_{F}=0.9\right.$ при $N=1 / 2$ ), и лишь затем начинают активно протекать процессы формирования Р3 при $N>1 / 2$. В случае КВД при 293 К динамическая рекристаллизация реализуется практически одновременно с началом процесса деформирования. При этом следует учесть, что определенный вклад в значение $C_{R G}$ на ранних стадиях КВД вносят также исходные зерна, соответствующие недеформированному состоянию. В целом максимальная относительная доля Р3 при $77 \mathrm{~K}$ составляет $C_{R G}=0.4$, в то время как при $293 \mathrm{~K} C_{R G}=0.6$. Вне зависимости от температуры КВД наблюдается очевидная тенденция к стабилизации относительных удельных объемов ДФ и РЗ по мере увеличения $N$, что,

Письма в ЖТФ, 2018, том 44, вып. 20 

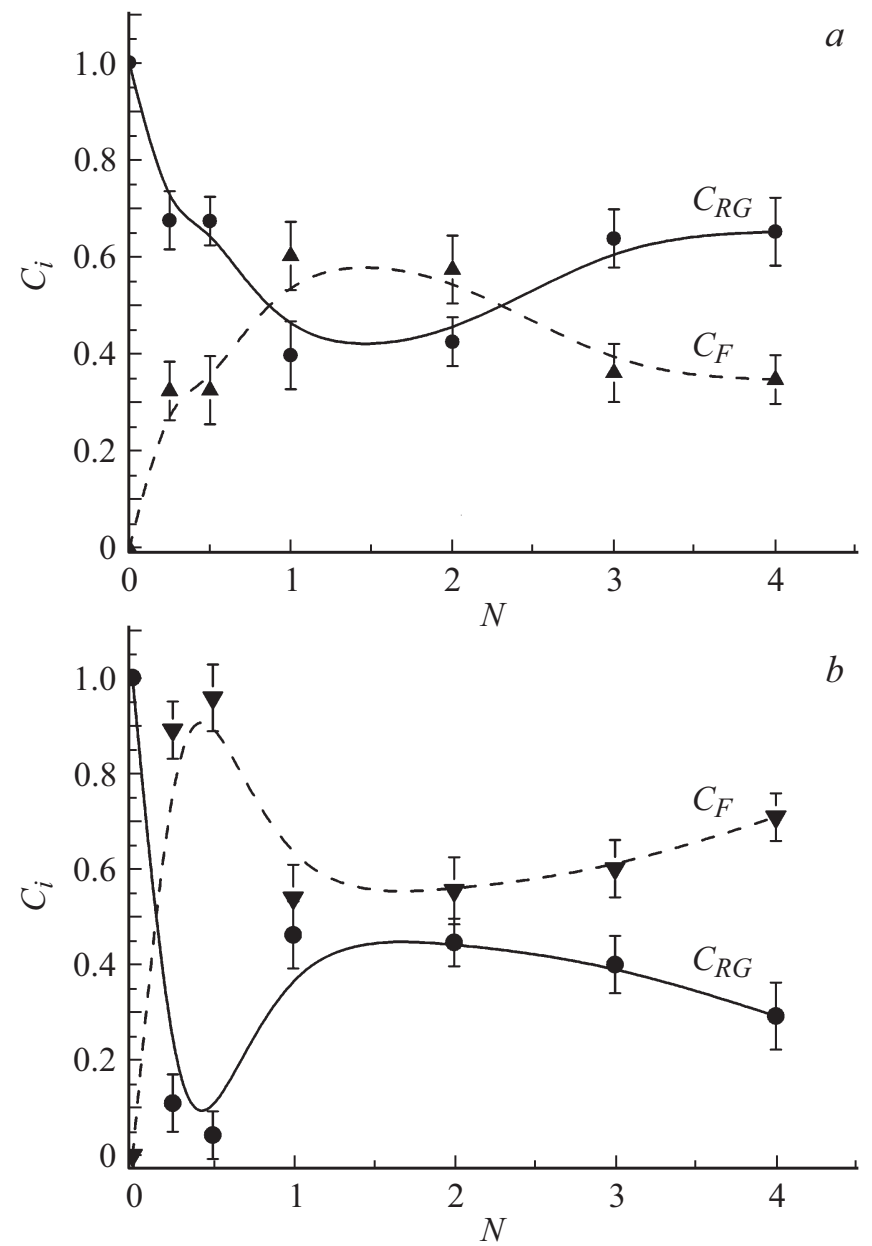

Рис. 2. Относительные объемные доли $\mathrm{P} 3$ и ДФ $\left(C_{R G}\right.$ и $C_{F}$ соответственно) в зависимости от $N$ при температурах КВД $293(a)$ и $77 \mathrm{~K}(b)$.

очевидно, является следствием формирования стационарной структуры в условиях процессов, подчиняющихся законам неравновесной термодинамики [8].

Письма в ЖТФ, 2018, том 44, вып. 20 

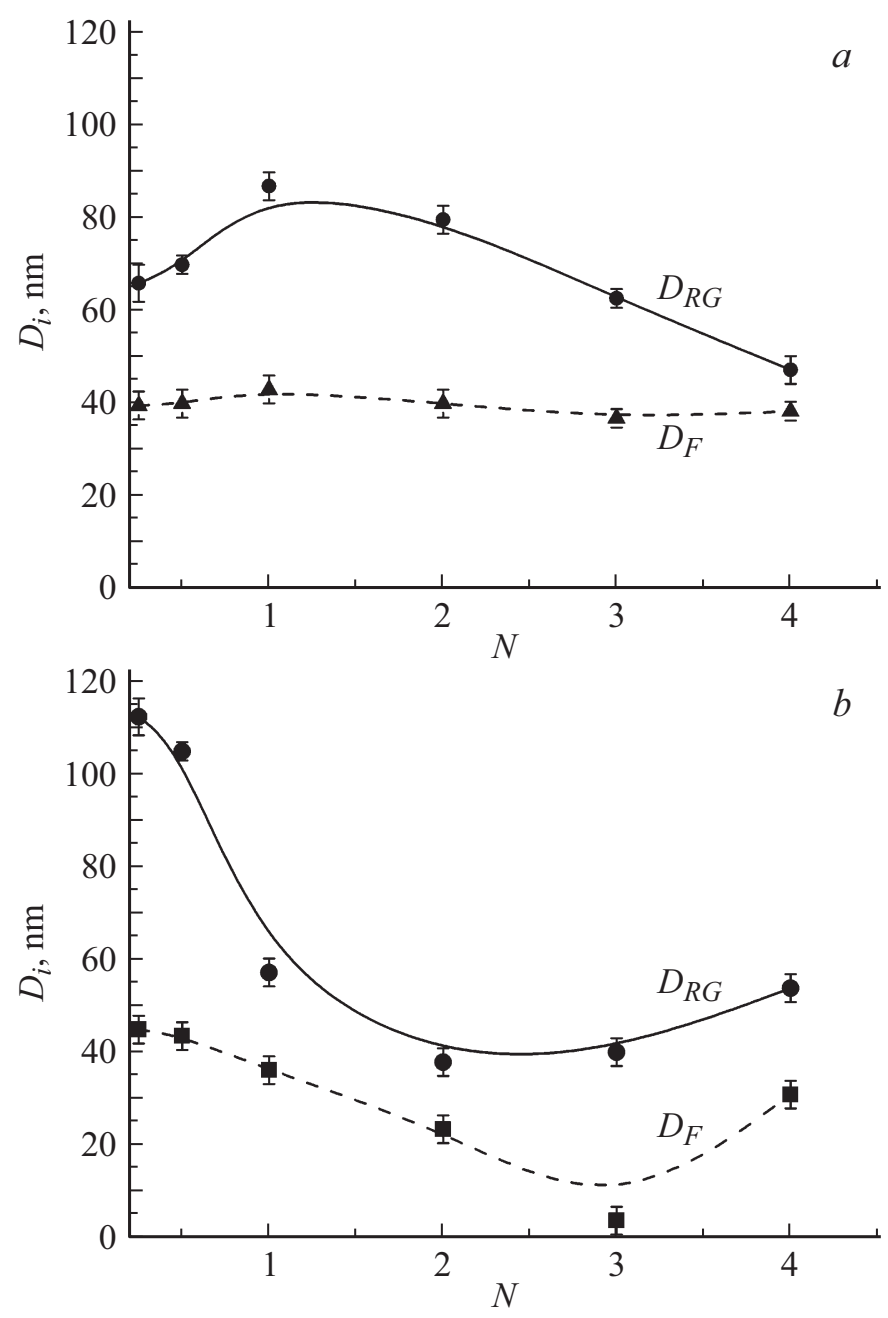

Рис. 3. Средние размеры областей для РЗ и ДФ $\left(D_{R G}\right.$ и $D_{F}$ соответственно) в зависимости от $N$ при температурах КВД $293(a)$ и $77 \mathrm{~K}(b)$.

Наиболее парадоксальный факт - протекание непрерывной динамической рекристаллизации при криогенных температурах дефор-

Письма в ЖТФ, 2018, том 44, вып. 20 
мирования - безусловно, связан с заметным выделением тепловой энергии. Мы исходим из того, что воздействие на твердое тело больших пластических деформаций следует рассматривать в рамках термодинамики неравновесных процессов как открытую механическую диссипативную систему, в которой полная механическая энергия непрерывно уменьшается или рассеивается, переходя в другие, немеханические формы энергии (упругую, химическую, тепловую и т.п.) [9]. При этом тепловая энергия является значимым каналом диссипации энергии пластической деформации в такой системе. Это приводит к кратковременному (несколько нано- или микросекунд) повышению температуры в локальных областях пластического сдвига на 500-600 K [10] и как следствие к протеканию кооперативных процессов перестройки дефектной структуры, которая ведет к появлению Р3. Детальный структурный механизм подобной перестройки еще предстоит проанализировать в дальнейших исследованиях.

Авторы выражают благодарность РФФИ за финансовую поддержку (проекты № 18-08-00640а и 18-08-00360а). Исследование структуры титана после криогенных деформаций проводилось в рамках государственного задания Министерства образования и науки РФ № $2017 / 113$.

\section{Список литературы}

[1] Zhilyaev A.P., Langdon T.G. // Prog. Mater. Sci. 2008. V. 53. N 6. P. 893-979.

[2] Рыбин В.В. Большие пластические деформации и разрушение металлов. М.: Металлургия, 1986. 224 с.

[3] Sakai T., Miura H., Goloborodko A., Sitdikov O. // Acta Mater. 2009. V. 57. N 1. P. $153-162$.

[4] Ivanisenko Yu., Kilmametov A., Rosner H., Valiev R.Z. // Int. J. Mater. Res. (formerly Z. Metallkd.). 2008. V. 99. N 1. P. 36-41.

[5] Humphreys F.J., Hatherly M. Recrystallization and related annealing phenomena. Amsterdam: Elsevier, 2004. 574 p.

[6] Глезер А.М. Большие пластические деформации // Основы пластической деформации наноструктурных материалов / Под ред. А.М. Глезера. М.: Физматлит, 2016. С. 206-259.

Письма в ЖТФ, 2018, том 44, вып. 20 
[7] Glezer A.M., Tomchuk A.A., Sundeev R.V., Gorshenkov M.V. // Mater. Lett. 2015. V. 161. P. 360-364.

[8] Метлов Л.С. Неравновесная эволюционная термодинамика и ее приложения. Донецк: Ноулидж, 2014. 176 с.

[9] Хаазе Р. Термодинамика необратимых процессов. Пер. с нем. М: Мир, 1967. $545 \mathrm{c}$.

[10] Glezer A.M., Timshin I.A., Shchetinin I.V., Gorshenkov M.V., Sundeev R.V., Ezhova A.G. // J. Alloys Compd. 2018. V. 744. P. 791-796. 